East African Medical Journal Vol. 80 No. 9 September 2003

LAPAROSCOPIC APPENDICECTOMY AT AGA KHAN HOSPITAL. NAIROBI

S.C. Patel. FRCS. FICS, EITS, Consultant Surgeon, Department of Surgery. The Aga Khan Hospital, P.O.Box 46256. Nairobi. G.F. Jumba. MD. PhD. Consultant Surgeon. Doctors Plaza, Aga Khan Hospital, P.O. Box 33803. Nairobi and S. Akmal, MBChB. Senior House Officer. Department of Surgery. The Aga Khan Hospital. P.O. Box 30270, Nairobi. Kenya

Request for reprints to: Dr. G.F. Jumba, Aga Khan Hospital, P.O. Box 3.3803, Nairobi, Kenya

\title{
LAPAROSCOPIC APPENDICECTOMY AT THE AGA KHAN HOSPITAL, NAIROBI
}

\author{
S. C. PATEL. G. F. JUMBA and S. AKMAL
}

\begin{abstract}
Objective: To evaluate our experience of laparoscopic appendicectomy at the Aga Khan Hospital, Nairobi over a six year period from the inception of the technique and to assess its advantages and disadvantages.

Design: Case series study.

Setting: The Aga Khan Hospital, Nairobi.

Patients: One hundred and six cases operated on from May 1996 to June 2002.

Main outcome measures: Clinical presentation, age and sex demographics, average hospital stay, operating time, intra-operative and post-operative complications and outcome.

Results: There was a female preponderance with a female to male ratio of $2: 3: 1$. Mean age was 30.6 years. There was a slightly more number of patients with recurrent appendicitis as opposed to the acute form. Totally laparoscopic procedure was in $39.6 \%$ of the cases, laparoscopic assisted in $45.3 \%$. The conversion rate to an open procedure was $15.1 \%$. Post operative port-site infection was $8.5 \%$. No mortality was reported in these series. However there was one case which required re-operation following significant port site haemorrhage. Mean post-operative hospital stay was 2.2 days. Conclusion: Laparoscopic appendicectomy is a safe procedure in well trained hands. The major advantages are less morbidity and excellent cosmesis. Discovery of other intraabdominal pathologies is possible through laparoscopy as opposed to classical appendicectomy.
\end{abstract}

\section{INTRODUCTION}

Appendicitis was first recognised as a disease entity in the sixteenth century and was called perityphlitis. Mcburney in 1889 described clinical findings of acute appendicitis prior to perforation with localisation of pain to the anatomic point that bears his name. Senn also in 1889 . was the first to report appendicectomy for acute appendicitis diagnosed prior to rupture. Conventional appendicectomy has been the "gold standard" for the treatment of acute appendicitis for more than a century (1).

Although it is a simple operation associated with a very low mortality rate, appendicectomy may result in significant post-operative morbidity particularly postoperative pain with overall post-operative complications occurring in $10-20 \%(2,3)$.

So it was of interest to evaluate laparoscopic appendicectomy with respect to these factors. The first laparoscopic appendicectomy was performed in 1983 by the pioneer of gynaecological laparoscopy, Kurt Semm (4).

Laparoscopic appendicectomy has been shown to be both feasible and safe in randomized comparisons with open appendicectomy. The introduction of video laparoscopy during the last decade has made widespread application of the procedure possible (5-8). Laparoscopic appendicectomy has shown to be of tremendous benefit especially when dealing with female patients and when symptoms of recurrent appendicitis are present.

\section{MATERIALS AND METHODS}

After initial proper training, a unit to perform laparoscopic procedures was set up at the Aga Khan Hospital, Nairobi. A three trocar American technique was used when performing totally laparoscopic appendicectomy and a two trocar for laparoscopic assisted appendicectomy. All the cases were performed within three units of the hospital by consultant surgeons and later by the registrars and senior house officers after initial training by assisting and later graduating to doing it under supervision and guidance.

A total of 828 cases of appendicectomies were reviewed over the study period. From May 1996 to June 2002, a total of 106 consecutive patients with a clinical diagnosis of acute appendicitis or recurrent appendicitis in the absence of obvious appendicular mass or abscess who underwent laparoscopic appendicectomy were included in the study.

Majority of the patients presented with right iliac fossa pain, nausea and vomiting. A base line haemogram, urea, electrolytes, creatinine and urinalysis were done in all the cases and in a minority of the cases, $C$-reactive protein was 
also done. Majority of the female patients underwent ultra sonography. Gross obesity was no contraindication to surgery. An action plan for a patient with suspected appendicitis is shown in Figure 1.

Patients were placed in supine position. All the cases were performed under general anaesthesia. The urinary bladder was then evacuated with an in and out catheter. In most of the patients, open pneumoperitoneum using the
Hasson technique was performed. In one of the units, pneumoperitoeum was created using a Veress needle. Insufflation with carbon dioxide at maximum pressure of $15 \mathrm{mmHg}$ and a total of 3 litres of gas is filled in before a $0^{\circ}$ or $30^{\circ}$ laparoscope is introduced into the abdominal cavity. The patient is then placed in the Trendelenberg position to allow the small bowel to fall out of the pelvis, (Figure 2).

Figure 1

Action plan for patients with suspected appendicitis (9)

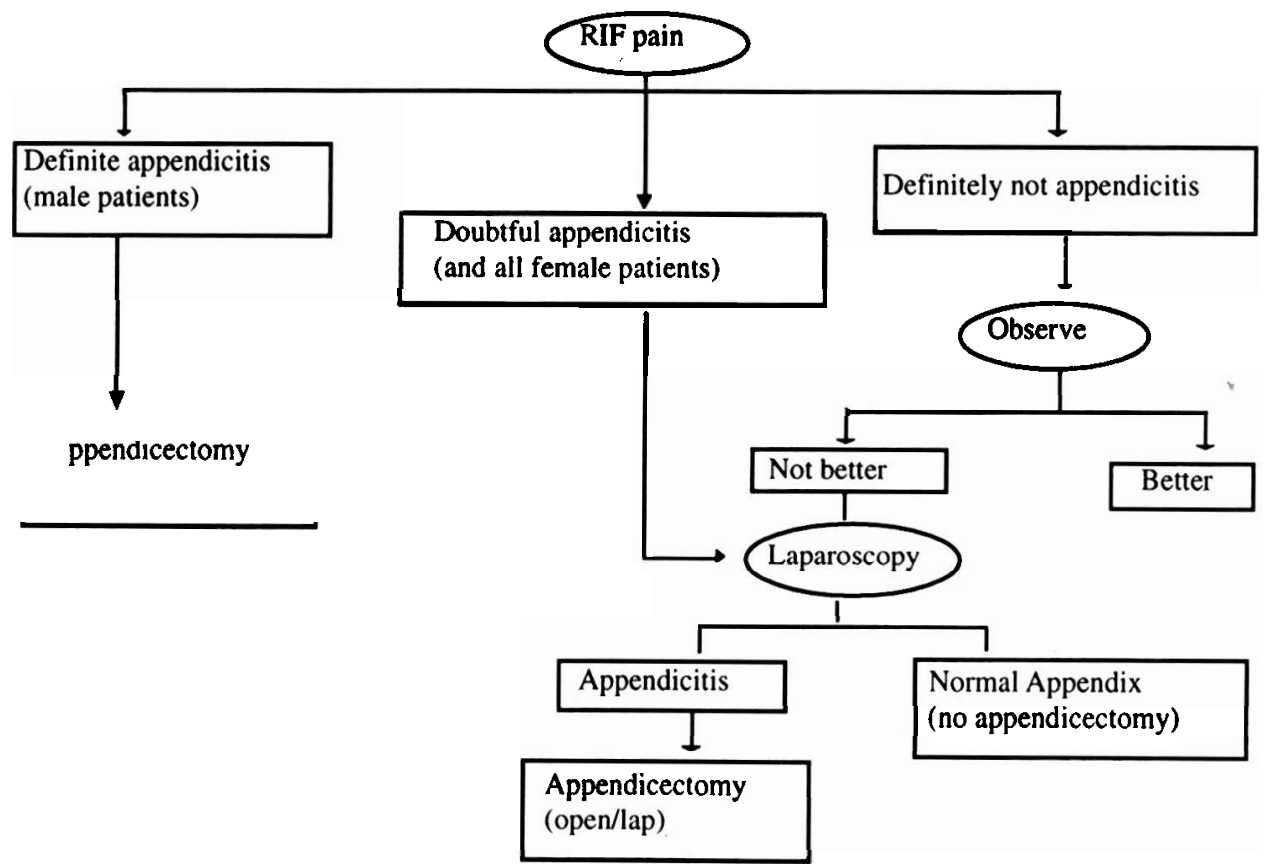

Figure 2

Placement of trocars (10)

$5 \mathrm{~mm}$ assisting port

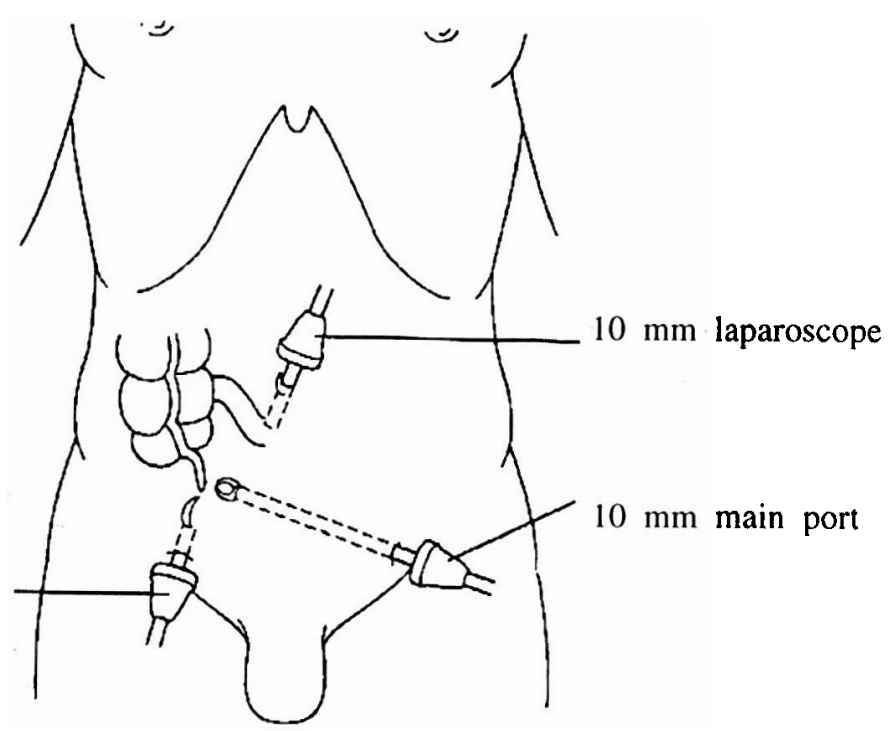


At this point, general abdominal inspection is done and the nature of pathology determined. All the subsequent trocars are then inserted under direct vision control on a television monitor. For totally laparoscopic appendicectomy, a five millimeter port is introduced in the right iliac fossa roughly to coincide with the base of the appendix and the third 10 millimeter trocar which is a working port is introduced into the abdominal cavity through the left iliac fossa. Signs of pathological evidence of appendicitis on laparoscopy are listed below.

- Free pus in right iliac fossa or peritoneal cavity.

- Appendix covered with omentum.

- Localised ileus at the area of the terminal ileum

- Adhesions in right iliac fossa area.

- Macroscopically the appendix is; swollen and congested, turgid, vessels injected, red and angry looking, distended lumen with faecolith, perforation, gangrene.

By way of transillumination, care is taken not to damage the inferior epigastric vessels and its branches. A nontraumatic palpator is then used to inspect the organs of the pelvis namely uterus, fallopian tubes, broad ligaments and the ovaries. A differential diagnosis of right-sided lower abdominal pain in young women of child-bearing age is outlined in Table 1.

\section{Table 1}

\section{Differential diagnosis in young women with right sided} lower abdominal pain (9)

\begin{tabular}{|c|c|c|}
\hline Diagnosis & $\begin{array}{l}\text { Laparoscopic } \\
\text { Intervention }\end{array}$ & $\begin{array}{l}\text { Open } \\
\text { surgery }\end{array}$ \\
\hline Acute appendicitis & Possible & May be required \\
\hline $\begin{array}{l}\text { Pelvic inflammatory } \\
\text { disease }\end{array}$ & Not required & Not required \\
\hline $\begin{array}{l}\text { Ruptured corpus } \\
\text { luteum cyst }\end{array}$ & Possible & Not required \\
\hline $\begin{array}{l}\text { Ruptured ovarian } \\
\text { follicle }\end{array}$ & Not required & Not required \\
\hline $\begin{array}{l}\text { Ruptured ectopic } \\
\text { pregnancy }\end{array}$ & Possible & May be required \\
\hline $\begin{array}{l}\text { Retrograde } \\
\text { menstruation }\end{array}$ & Not required & Not required \\
\hline Endometriosis & Not required & Not required \\
\hline Primary peritonitis & Possible & May be required \\
\hline Twisted ovarian cyst & Possible & May be required \\
\hline
\end{tabular}

The appendix is then grasped with a Babcock type of forceps through a five millimeter trocar in the right iliac fossa. This helps tense the mesoappendix for easier dissection. Through the $10 \mathrm{~mm}$ port, the mesoappendix and appendicular artery are cauterised using a monopolar diathermy hook. Any adhesions in the right jliac fossa are released laparoscopically first by coagulation then followed by sharp dissection. The base of the appendix is then fully but carefully skeletonised without undue injury to the caecum and terminal ileum. Through the $10 \mathrm{~mm}$ port, three Roders endoloop knots of polydioxanone $1 / 0$ are then applied to the base of the appendix with the two proximal knots in close proximity and the distal one being $5 \mathrm{~mm}$ at then. Appendicectomy is then completed with the resultant two polydioxanone Roders knots on the appendicular stump.

The cut end of the appendix is then grasped with grasping forceps and retrieved. Thorough warm saline wash is done. This not only removes blood clots but also removes inflammatory fluid. At the end 500 c.c. of normal saline is left in the peritoneal cavity in order to reduce post operative pain. The two iliac fossa ports are removed under direct vision and the wounds are then closed.

As for laparoscopic assisted appendicectomy. Iwo trocars are usually used, a $10 \mathrm{~mm}$ port for telescope insertion at the umbilical area and $5 \mathrm{~mm}$ trocar in the right iliac fossa preferably at Mcburney's point. General abdominal inspection is done. If the appendix turns out to be pathological. then the appendix tip is gasped preferably with a Babcock type of forceps. It is then delivered out through the right iliac fossa puncture wound. At this juncture, carbon dioxide is deflated from the abdominal cavity and appendicectomy completed the classical way.

If intra abdominal adhesions are encountered. then a third port is inserted in left iliac fossa and adhesiolysis performed before appendicectomy is completed. Finally. the right iliac fossa area and pelvic region are thoroughly irrigated with warm saline. We like instilling undiluted rifocin in the right iliac fossa as antiseptic. The two ports in right and left iliac fossa are then withdrawn under direct vision. The umbilical port is withdrawn last and wounds closed.

A summary of the technique of laparoscopic appendicectomy is shown below:

(i) Confirm the diagnosis.

(ii) Conduct a general laparoscopic examination.

(iii) Identify the tip and base of the appendix.

(iv) Ligate the mesoappendix close to the appendix and dissect until a clean healthy base is exposed.

(v) Secure the base with one or two Roeder loops [Endoloop] of polydioxanone; place a clip distally to minimise spillage.

(vi) Transect the appendix 5 to $7 \mathrm{~mm}$ from the tic: briefly coagulate the stump

(vii) Extract the appendix without wound contamination.

(viii) Irrigate the operative site, pelvis, and right paracolic gutter with saline.

We give prophylactic antibiotics of two doses and in septic cases antibiotics are continued for up to five days.

\section{RESULTS}

There were 106 cases from May 1996 till June 2002 , of which $74(69.8 \%)$ were females while males were $32(30.2 \%)$. The female to male ratio was $2.3: 1$. The youngest patient was 10 years and the oldest 58 years with a mean age of 30.6 years. Eighty one cases were in African patients, 18 in Asians and seven in Caucasians. There were 51 cases who presented with acute appendicitis and 55 with recurrent appendicitis. Evolution of laparoscopic appendicectomy at Aga Khan Hospital on yearly basis is as shown in Table 2 . 
Table 2

Percentage of laparoscopic appendicectomies on yearly basis

\begin{tabular}{llll}
\hline Year & $\begin{array}{l}\text { No. of all } \\
\text { appendicectomies }\end{array}$ & $\begin{array}{l}\text { No. of lap. } \\
\text { appendicectomies }\end{array}$ \\
\hline Jan-June 2002 & 80 & 28 & 35 \\
2001 & 133 & 39 & 29.3 \\
2000 & 152 & 18 & 11.8 \\
1999 & 162 & 10 & 6.2 \\
1998 & 118 & 7 & 5.9 \\
1997 & 129 & 2 & 1.6 \\
From May 1996 & 54 & 2 & 3.7 \\
\hline Total & 828 & 106 & 12.8 \\
\hline
\end{tabular}

Fourty eight of the cases were done using the laparoscopic assisted method, 42 totally laparoscopic and 16 cases were converted to open. The reasons for conversion are illustrated in Table 3.

Table 3

Reasons for conversion

\begin{tabular}{ll}
\hline Appendicular abscess & 1 \\
Retrocaecal appendix & 5 \\
Slip of loop from appendix stump & 1 \\
Necrosed fragmented appendix & 3 \\
Failure of light source & 1 \\
Leaking valves & 2 \\
Massive adhesions & 2 \\
Early learning curve & 1 \\
\hline Total & 16 \\
\hline
\end{tabular}

Histologically, $94(88.7 \%)$ of the cases were pathological and $12(11.3 \%)$ were reported as normal. Of the pathological cases, 45 were acutely inflamed and 47 were chronically inflamed. There were two cases of carcinoid tumour.

Average hospital stay was 3.35 days with the shortest stay being one day and the longest 12 days. Post-operative average hospital stay was 2.24 days with a variation of 1 to 10 days. Mean operating time was 1 hour 30 minutes with the shortest operating time being 35 minutes and the longest three hours.

Complications: In these series, no mortality was recorded. Post operative wound infection was noted in nine patients $(8.5 \%)$. There were eight cases of port site infection, four in the totally laparoscopic arm and four in the laparoscopic assisted group. One patient developed infection following conversion to open due to appendicular abscess. All the wound infections were managed conservatively. Post-operative wound haemorrhage developed in one patient. The source of haemorrhage was found to be a muscle bleeder from one of the 10 millimeter port site incision in the right iliac fossa area. On the 2 nd post-operative day, the port site incision was converted to a Lanze incision and the source of bleeding arrested.

\section{DISCUSSION}

The breakthrough in laparoscopy occurred during the last decade in conjunction with the introduction of laparoscopic cholecystectomy into clinical practice. In this study, there was a steady increase in the number of cases of appendicitis being handled laparoscopically.

This is a result of improved surgical skills and patient driven desires as more of our population get to know about laparoscopic procedures. The numbers are however still below those seen in developed countries. In this series, laparoscopic appendicectomy was almost equally performed for both acute and recurrent appendicitis.

Laparoscopic appendicectomy is a relatively safe procedure which can be mastered by junior surgeons in their early learning curve as opposed to laparoscopic cholecystectomy. Our average operating time was I hour 30 minutes partly because of the learning curve by the junior surgeons which eventualiy improved with time due to increasing experience as reported earlier by other authors (11-14).

In this study, we found out that laparoscopic procedure has other advantages over open method especially as concerns other intra-abdominal pathologies such as adhesions. Conversion to open appendicectomy in our study was found to be $15.1 \%$ which compares favourably with rates of $6 \%$ to $23 \%$ from different international centres (15-18). Increasing experience with laparoscopic procedures will hopefully result in lower conversion rates.

In the present study, we did not encounter any case of post-operative intra-abdominal abscess as evidenced in many other international studies (11). This could be explained by the fact that majority of very acutely inflamed appendices were performed classically.

However, port site infections and one wound infection after conversion to open were noted in $8.5 \%$ of the cases. Our results compare favourably with international figures which range from $2 \%-23 \%$ $(2,3,5,6,14,19,20)$. This may be explained by the fact that there were few very septic cases in our study and that we routinely used antiseptics during irrigation and suction of the abdominal cavity.

Transillumination of the anterior abdominal wall can prevent vascular injuries of the anterior abdominal wall during trocar insertion. Our mean hospital stay was 3.35 days which is in keeping with several other international statistics which report a median hospital stay of $2-5$ days $(2,3,5,8,11,20-23)$.

Underutilization of laparoscopy as far as appendicitis is concerned at our institution could be attributed to failure to use laparoscopy after normal working hours due to understaffing and poor knowledge of laparoscopy by junior surgeons who usually encounter cases of acute appendicitis after normal working schedule.

This problem can be corrected if serious laparoscopic training can be introduced at our teaching institutions 
and scepticism for both old and young surgeons can be replaced by genuine positive interest in laparoscopy.

In conclusion, we believe that laparoscopic surgery has tremendous potential in this part of the world as it will be patient driven as more and more patients continue to experience its advantages namely:-

(i) confirms the diagnosis

(ii) shorter post-operative convalescence

(iii) reduced hospital stay

(iv) reduced wound infection

(v) minimises scars

(vi) allows earlier return to normal activities

(vii) may reduce postoperative adhesions

(viii) offers good laparoscopic training

\section{ACKNOWLEDGEMENTS}

To the Medical Director, Aga Khan Hospital, Nairobi for permission to publish this study.

\section{REFERENCES}

Fitz, R. Perforating inflammation of the vermiform appendix, with special reference to its early diagnosis and treatment. Am. J. Med. 1886; 92:321-346.

Pieper, R., Kager, L., and Nasman, P. Acute appendicitis: a clinical study of 1018 cases of emergency appendectomy.

Acta. Chirurgica Scandinavica. 1982; 148: 5I-62.

Chiaruga, M., Buccianti, P., Celona, G. et al. Laparoscopic compared to open appendicectomy for acute appendicitis: a prospective study. Eur. J. Surg. 1996; 162:385-390.

Semm, K. Endoscopic appendectomy. Endoscopy. 1983; 15:59-64.

Kum, C.K.. Ngoi, S.S., Goh, P.M.Y, et al. Laparoscopic versus open appendicectomy: a prospective evaluation. Brit. J. Surg. 1992; 79:818-820.

Ortega, A.E., Hunter. J.G., Peters, J.H., Swanstrom. L.L., and Schirmer, B., The Laparoscopic Appendectomy Study Group. A prospective, randomized comparison of laparoscopic appendectomy. Am. J. Surg. 1995; 169:208213.

7. Attwood, S.E..A., Hill, A.D.K., Murphy, P.G., Thornton, J., and Stephens, R.B. A prospective randomized trial of laparoscopic versus open appendectomy. Surgery. 1992; 112:497-501.

8. Hansen, J.B, Smithers, B.M., Schache, D., et al. Laparoscopic versus open appendectomy: prospective randomized trial. World J. Surg. 1996; 20:17-21.

9. Jager R.M. and Wexner S.D. Laparoscopic colorectal Surgery. Churchill Livingstone. 1996; 173:167-169.

10. Monson, J. Duthie, G. and O'Malley, K. Surgical emergencies Blackwell Sciences. 1999; 93-97

11. Pedersen, A.G., Petersen, O.B., Wara, P., et al.. Randomised clinical trial of laparoscopic versus open appendicectomy. Brit. J. Surg. 2001; 88:200-205.

12. Lintula, H., Kokki, H., and Vanamo, K. Single-blind randomized clinical trial of laparoscopic versus open appendicectomy in children. Brit. J. Surg. 2001; 88:510514.

13. Valla, J.S., Limonne, B., Valla, V., el al. Laparoscopic appendectomy in children: report of 465 cases. Surg. Laparosc. Endosc. 1991; 1:166-172.

14. Peters, J.H., Ellison, E.C., Innes, J.T., et al. Safety and efficacy of laparoscopic cholecystectomy. A prospective analysis of 100 initial patients. Ann. Surg. 1991; 213:312.

15. Hellberg, A., Rudberg. C., Kullman, E.. et al. Prospective randomized multicentre study of laparoscopic versus open appendicectomy. Brit. J. Surg. 1999: 86:48-53.

16. Martin, L.C., Puente I., Sosa, J.L., et al. Open versus laparoscopic appendectomy: prospective randomized comparison. Ann. Surg. 1995; 222:256-262.

17. Cox, M.R, McCall, J.L., Toouli, J., et al. Prospective randomized comparison of open versus laparoscopic appendectomy in men. World. J. Surg. 1996: 20:263-266.

18. Tate, J.J.T., Chung. S.C.S., Dawson, J., et al. Conventional versus laparoscopic surgery for acute appendicitis. Brit. $J$. Surg. 1993; 80:761-764.

19. Mccall, J.L, Sharples, K., and Jadallah. F. Systematic review of randomized controlled trials comparing laparoscopic with open appendicectomy. Brit. J. Surg. 1998; 12:1204-1208.

20. Blind, P.J., and Dahlgren, S.T. The continuing challenge of the negative appendix. Acta Chirurgica Scandinavica. 1986; 152:623-627.

21. Reiertsen, O., Larsen, S., Trondsen, E., et al. Randomized controlled trial with sequential design of laparoscopic versus conventional appendicectomy. Brit. J. Surg. 1997; 84:842-847.

22. Heikkinen, T.J., Haukipuro, K., and Hulkko. A. Costeffective appendectomy. Open or laparoscopic? A prospective randomized study. Surg. Endosc. 1998; 12:1204-1208.

23. Tate, J.J.T., Dawson, J.W., Chung, S.C.S., Lau, W.Y., and Li, A.K.C. Laparoscopic versus open appendicectomy: prospective randomized trial. Lancet. 1993; 342:633-637. 